\title{
PROJECTING CHANGES IN COASTAL MORPHOLOGY BY SATISFYING PREREQUISITE CONDITIONS OF SLAMM SOFTWARE IN CONTEXT OF SUNDARBAN

\author{
Anasua Chakraborty ${ }^{1}$, Alolika Basu ${ }^{1}$, Nandita Mukherjee ${ }^{1 *}$, Navendu Chaudhary ${ }^{1}$, Kankana Chakraborty ${ }^{2}$
}

\author{
${ }^{1}$ Symbiosis Institute of geoinformatics, 5th and 6th Floor, Atur Centre geoinformatics, Gokhale Cross Road, Model Colony, Pune -, \\ 411016, Pune, Maharashtra-411016, anasua40chakraborty@gmail.com \\ ${ }_{2}$ junior analyst, ESRI INDIA, H-7 Noida, 201301
}

Commission V, SS: Atmosphere, Ocean, Weather and Climate

\section{KEYWORDS:}

Sea Level Affecting Marshes Model(SLAMM), National Wetlands Inventory, from US Fish and Wildlife Service(NWI), National Wetlands Inventory, from US Fish and Wildlife Service(NAVD 88), Sea Level Rise, Great Diurnal Tide Range(GT), Mean Higher High Water(MHHW), Mean Lower Low Water(MLLW), Mean Tide Level(MTL).

\begin{abstract}
:
RS and GIS data have been acquired as a primary source for study. The satellite images mainly show the temporal changes in coastal morphology and shorelines of the area. The main aim is to analyze the applicability of a platform called SLAMM or Sea Level Affecting Marshes Model to predict the changes related to the different kinds of ecosystems in the Sundarbans with the eustatic rise in sea level. A satellite image (LANDSAT) of the year 2001 of the study area was used as a base map. Using this base map, an attempt has been made to forsee the morphological changes to the ecosystems up to the year 2016 using SLAMM (Payo, et al., 2016). It has investigated the changes in coastal scenario and also its effect on the vegetation and other factors of sundarban. The results indicate that tidal flats are increasing along with the year thus degrading the ocean beach and the amount of vegetation coverage, especially that of mangroves which has degraded between these years and may predict its changes up till the end of $21^{\text {st }}$ century. The SLAMM software will also show the accuracy depending on the calibration and SLR depending on MSL and MTL to that of the real world scenario. Hence the final output will facilitate us with certain future scope which may help for better and bigger approaches of study towards the development of coastal management.
\end{abstract}

\section{INTRODUCTION:}

The Sea Level Affecting Marshes Model (SLAMM) simulates the dominant processes involved in wetland conversions and shoreline modifications during long-term sea level rise (Technical Documentation, SLAMM 6.2). SLAMM was introduced in the mid-1980s. A decision tree that incorporates geometric and qualitative relationships operates as the backbone for the simulation. The five primary processes used to predict wetland fate with SLR are inundation, erosion, over wash, saturation and accretion.

SLAMM was designed primarily for the western countries. A number of government projects related to the protection of wetlands were speculated based on the results predicted by SLAMM in the U.S.A. Geselbracht, et al., (2011) conducted a hind cast in which they compared model results to 30 years of field plot data in the State of Florida, USA. Overall, the model showed the same pattern of coastal forest loss as observed. Consequently, an assumption or fair enough statement can be made that SLAMM can make nearly accurate predictions related to coastal morphological changes, provided the input parameters are precise and applied to analyze and project changes in the coastal areas .

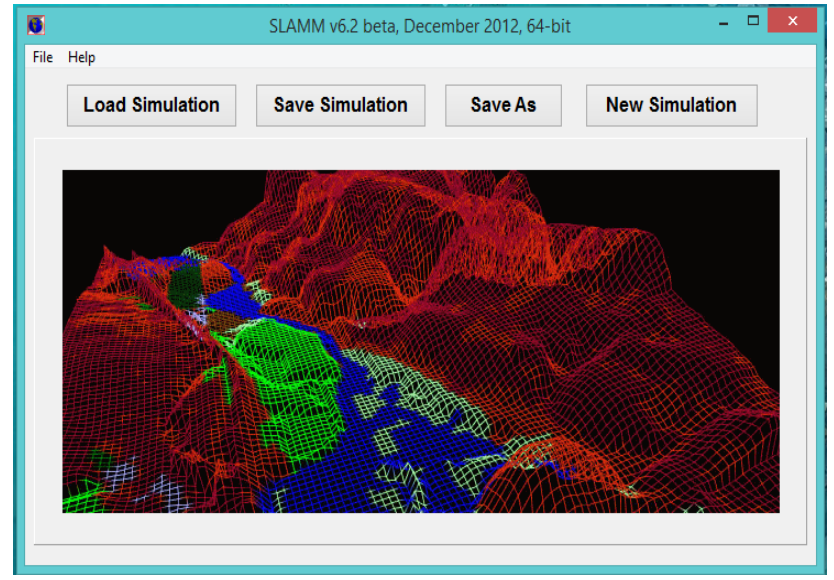

Figure 1: SLAMM 6.2 Opening Screen

*corresponding author: nandita.noni@gmail.com 


\section{LITERATURE REVIEW:}

The Sundarbans mangrove forest, one of the largest forests in the world (140,000 ha), lies on the delta of the Ganges, Brahmaputra and Meghna rivers on the Bay of Bengal. It is adjacent to the border and claimed as India's World Heritage site inscribed in 1987. The site is intersected by a complex network of tidal waterways, mudflats and small islands of salt-tolerant mangrove forests, and presents an excellent example of ongoing ecological processes. The area is known for its wide range of fauna, including 260 species of bird, the Bengal tiger and other threatened species such as estuarine crocodile and Indian python. The Sundarbans Reserve Forest (SRF), located in the south-west of Bangladesh between the river Baleshwar in the East and the Harinbanga in the West, adjoined by to the Bay of Bengal, is the largest contiguous mangrove forest in the world lies between $21^{\circ} 27^{\prime} 30^{\prime \prime}$ latitude and $22^{\circ} 30^{\prime} 00^{\prime \prime}$ North and longitude $89^{\circ} 02^{\prime} 00^{\prime \prime}$ and $90^{\circ} 00^{\prime} 00^{\prime \prime}$ East covering a total area of 10,000 $\mathrm{km}^{2}, 60 \%$ of the property lies in Bangladesh and the rest in India. The land area including exposed sandbars occupies 414,259 ha $(70 \%)$ with water bodies covering 187,413 ha $(30 \%)$. The immense tidal mangrove forests of Bangladesh and Sundarbans Forest Reserve, is in reality a mosaic of islands of different shapes and sizes, perennially washed by brackish water shrilling in and surrounded by the endless labyrinths of water channels. Thus mainly a study has been done in order to see the changes of the coastal morphology of that area over the years, where applicability of slamm is being taken.

\section{SLAMM}

The Sea Level Affecting Marshes Model (SLAMM) simulates the dominant processes involved in wetland conversions and shoreline modifications during long-term sea level rise. Map distributions of wetlands are predicted under certain conditions which includes accelerated sea level rise and the results of which are summarized. SLAMM has been used in several geographies and their applications across the nation since its development in the mid-1980s (The Nature Conservancy, Rhode Island Chapter). Thus it projects the potential changes under future scenarios depending on calibration and different sea level rise (for example $1,3,5$ meters of range).It demarcates areas protected by dikes and other hard structures, along with sedimentation and accretion rates and provide options for computing erosion of coastal wetland classes. Thus the outputs can be viewed in a geographic information system (GIS) or other software for additional analysis.

\section{SLAMM contains certain disadvantages which are:}

1. It is sensitive to cell size and resolution thus works better on images with finer resolution. It is not sensitive to any natural calamity (warren pinnacle consultancy Inc.) which is anyway not possible for any model to predict. It takes into account the parameters of that classification which is same as the Slam technical tree of classes.

2. The Sea Level Affecting Marshes Model (SLAMM) simulates the dominant processes involved in wetland conversions and shoreline modifications during longterm sea level rise.

3. Tidal marshes can be among the most susceptible ecosystems to climate change, especially accelerated sea level rise (SLR) (DRAFT December 11, 2012).

So this project is mainly concentrating on area of sundarban for the year 2001 and 2016 where we can show all other degradation of coastal dynamics comparing the two years, taking into account the Mangrove, ocean beach, Open Ocean and tidal creek or swamp and thus conclude the prediction accuracy with respect to its subsidence rate.

\begin{tabular}{|c|c|}
\hline SLAMM code & Class name \\
\hline 1 & Developed Dry Land \\
\hline 2 & Under Developed Dry Land \\
\hline 3 & Non-tidal Swamp \\
\hline 4 & Cypress Swamp \\
\hline 5 & Inland Fresh Marsh \\
\hline 6 & Tidal Fresh Marsh \\
\hline 7 & Transition Marsh/Scrub Shrub \\
\hline 8 & Regularly Flooded Marsh(Salt marsh) \\
\hline 9 & Mangrove \\
\hline 10 & Estuarine Beach \\
\hline 11 & Tidal Flat \\
\hline 12 & Ocean Beach \\
\hline 13 & Ocean Flat \\
\hline 14 & Rocky Intertidal \\
\hline 15 & Inland Open Water \\
\hline 16 & Riverine Tidal Open Water \\
\hline 17 & Estuarine Open Water \\
\hline 18 & Tidal Creek \\
\hline 19 & Open Ocean \\
\hline 20 & Irregularly Flooded Marsh \\
\hline 21 & Not Used \\
\hline 22 & Inland Shore \\
\hline 23 & Tidal Swamp \\
\hline
\end{tabular}

Table1: SLAMM categories/classes according to National wetland Inventory 


\section{STUDYAREA:}

The Sundarbans is a natural region in southern Bangladesh and the extreme southern part of the Indian state of West Bengal in the vast river delta on the Bay of Bengal. It is the largest single block of tidal halophytic mangrove forest in the world extending from $21.9497^{\circ} \mathrm{N}, 89.1833^{\circ} \mathrm{E}$. We are mainly focusing on an island situated in the eastern part of Lothian Island.

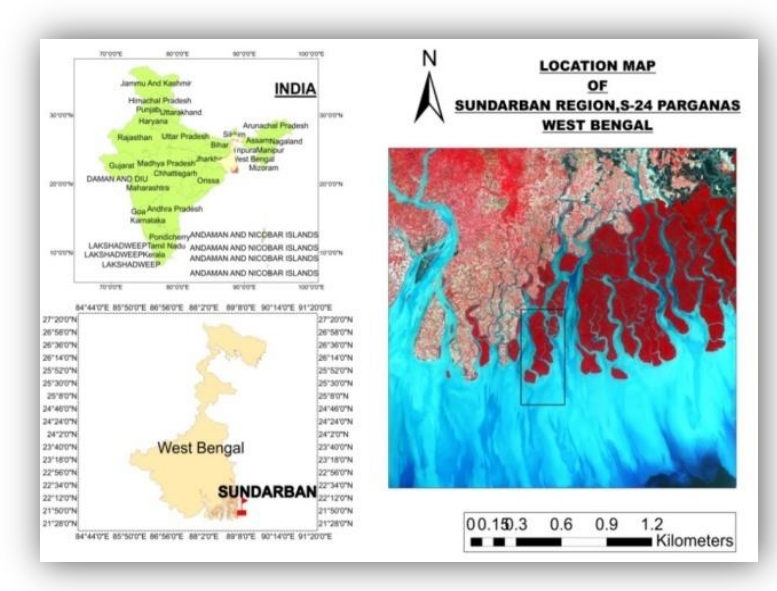

Figure 2: Study Area Sundarban South 24 Parganas

\section{DATA COLLECTION:}

In this part there is a brief discussion of the data that has been used during the analysis, pre-processing techniques and all the processing methods that were performed in the study. Several remote sensing data processing methods were utilized in order to carry out this project: image classification, Digital image classification and slope map.

Software

I. Intergraph ERDAS Imagine 2014

II. ArcMap 10.1.2

III. Microsoft Office Excel

\section{DATA ACQUISITION:}

Landsat 7, the Enhanced Thematic Mapper Plus (ETM+), replicates the capabilities of the highly successful Thematic Mapper instruments on Landsat 4 and 5. The ETM + also includes new features that make it a more versatile and efficient instrument for global change studies, thermal studies, forest cover monitoring land cover monitoring and assessment and large area mapping (http://geo.arc.nasa.gov/sge/landsat/17.html).Landsat8 joins Landsat7 on orbit providing increased coverage of the Earth's surface. Multi-Spectral Landsat data for Sundarbans for two different time periods was acquired from the most preferred source of Landsat data collect i.e., United States Geological Survey (USGS) earth Explorer (http//:earthexplorer.usgs.gov/).Data collected has zero/minimal cloud cover. Landsat 7 and 8 data were utilized to carry out this project.

\begin{tabular}{|l|l|l|l|l|}
\hline $\begin{array}{l}\text { Sl } \\
\text { no }\end{array}$ & $\begin{array}{l}\text { Satellite } \\
\text { Images }\end{array}$ & Sensor & $\begin{array}{l}\text { Date } \\
\text { of } \\
\text { acquis } \\
\text { ition }\end{array}$ & $\begin{array}{l}\text { Path/Ro } \\
\text { w }\end{array}$ \\
\hline 1 & LANDSAT7 & ETM+ & $\begin{array}{l}17 / 11 / \\
2001\end{array}$ & $138 / 45$ \\
\hline 2 & LANDSAT8 & ETM+ & $\begin{array}{l}15 / 12 / \\
2016\end{array}$ & $141 / 45$ \\
\hline
\end{tabular}

Table 2: Data Acquisition detail

\begin{tabular}{|c|c|c|c|c|c|}
\hline \multicolumn{3}{|c|}{ Landsat-7 ETM+Bands (um) } & \multicolumn{3}{|c|}{ Landsat-8 OLI and TIRS Bands (um) } \\
\hline & & & $30 \mathrm{~m}$ Coastal/Aerosol & $0.435 \cdot 0.451$ & Band 1 \\
\hline Band 1 & $30 \mathrm{~m}$ Blue & $0.441 \cdot 0.514$ & $30 \mathrm{~m}$ Blue & $0.452 \cdot 0.512$ & Band 2 \\
\hline Band 2 & $30 \mathrm{~m}$ Green & $0.519 \cdot 0.601$ & $30 \mathrm{~m}$ Green & $0.533 \cdot 0.590$ & Band 3 \\
\hline Band 3 & $30 \mathrm{mRed}$ & $0.631 \cdot 0.692$ & $30 \mathrm{mRed}$ & $0.636 \cdot 0.673$ & Band 4 \\
\hline Band 4 & $30 \mathrm{~m} \mathrm{NIR}$ & $0.772 \cdot 0.898$ & $30 \mathrm{mNR}$ & $0.851 \cdot 0.879$ & Band 5 \\
\hline Band 5 & $30 \mathrm{~m}$ SWIR-1 & $1.547 \cdot 1.749$ & $30 \mathrm{~m}$ SWIR.1 & $1.566 \cdot 1.651$ & Band 6 \\
\hline \multirow[t]{2}{*}{ Band 6} & \multirow[t]{2}{*}{$60 \mathrm{~m} T \mathrm{R}$} & \multirow[t]{2}{*}{$10.31 \cdot 12.36$} & 100 m TIR-1 & $10.60-11.19$ & Band 10 \\
\hline & & & $100 \mathrm{~m}$ TIR-2 & $11.50-12.51$ & Band 11 \\
\hline Band 7 & $30 \mathrm{~m}$ SWIR-2 & $2.064 \cdot 2.345$ & $30 \mathrm{~m}$ SWIR-2 & $2.107-2.294$ & Band 7 \\
\hline \multirow[t]{2}{*}{ Band 8} & $15 \mathrm{mPan}$ & $0.515 \cdot 0.896$ & $15 \mathrm{~m}$ Pan & $0.503 \cdot 0.676$ & Band 8 \\
\hline & & & $30 \mathrm{~m}$ Cirrus & $1.363 \cdot 1.384$ & Band 9 \\
\hline
\end{tabular}

Table 3: Sensor Details 


\section{METHODOLOGY:}

\section{PREPROCESSING}

Pre-processing usually consists of a sequence of operations, the number and order of which is defined by the aim of the research and the type of data received from satellite operator/satellite image distributor. Main steps include:

1. The Landsat files come in "one band per image", therefore, Layer stacking has been done with all the bands to get the final image for performing the further steps.

2. In most cases of study, Landsat scene had much larger extent than the area of interest. In order to reduce file size, original scenes were subset by region of interest. Layer Stacking and Subset have been performed in ERDAS Imagine 2014. The subset image was further masked to obtain the study area in ArcMap 10.1.2 using the Extract by Mask function

3. Before exporting the data (Satellite image and DEM file) the cell size of both was matched i.e. the cell size of the DEM file was changed to the same cell size as that of the Satellite Image.

4. Supervised classification was being carried on as per the slam classes under five categories for generating the NWI data on which the software will operate.

\section{PROCESSING:}

Processing usually consists of the following sequence of operations. While preprocessing shows the refinement of the raw images, the processing mainly initiates the examining, analysis and final output thus satisfying objective. Thus the flowchart shows the workflow which has been opted in the project to get completed.

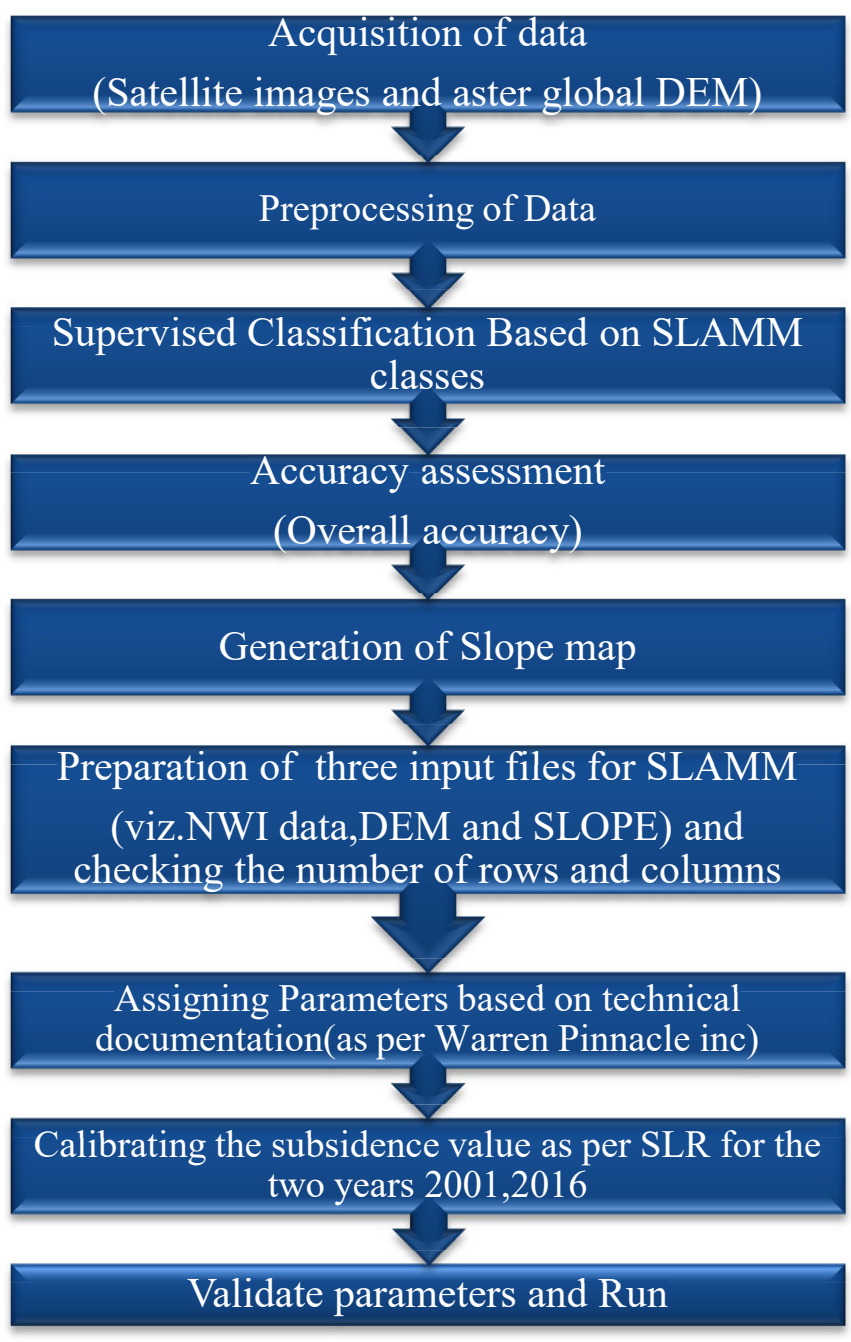

\section{THE FUNDAMENTAL INPUTS OF SLAMM}

For the project, the 6.2 version of SLAMM (SLAMM version 6.2 beta-64bit was used to simulate the morphological changes related to the ecosystems present within the area for the period of 2000 to 2016. (SLAMM version 6.2 beta-64bit, http://warrenpinnacle.com). Wetlands inhabit a range of vertical elevations that is a function of the tidal range. Among the five primary processes integrated within SLAMM (inundation, erosion, overwash, saturation, accretion), we have only considered inundation, erosion and accretion. As coastal swamps and fresh marshes categories are not present in the study zone, upland migration of coastal swamps and fresh marshes as a response to the fresh water table rising- is excluded. The absence of beaches leads to the exclusion of over wash parameter. 
Estuarine beaches and tidal flats are assumed to erode at the same user defined erosion rate. Only one change of wetland category is allowed at each time step. The primary file input for SLAMM is the Digital Elevation Model (DEM) and the National Wetland Inventory (NWI). Table 6 gives a summary of the input parameters used for our simulation National Wetland Inventory.

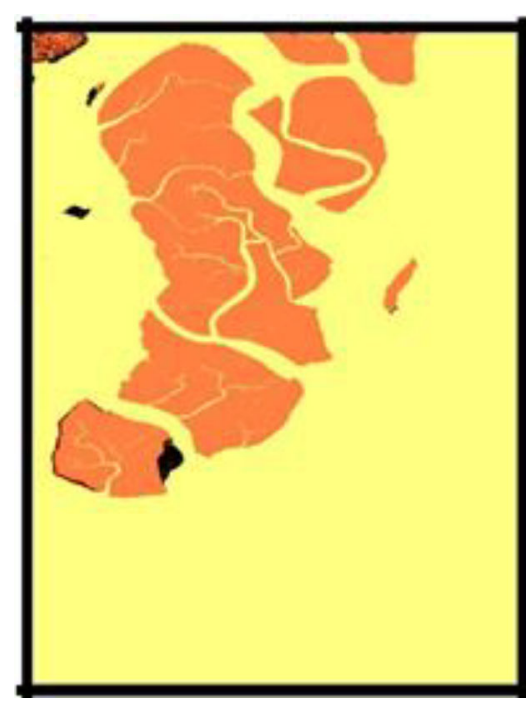

(a) Year-2001

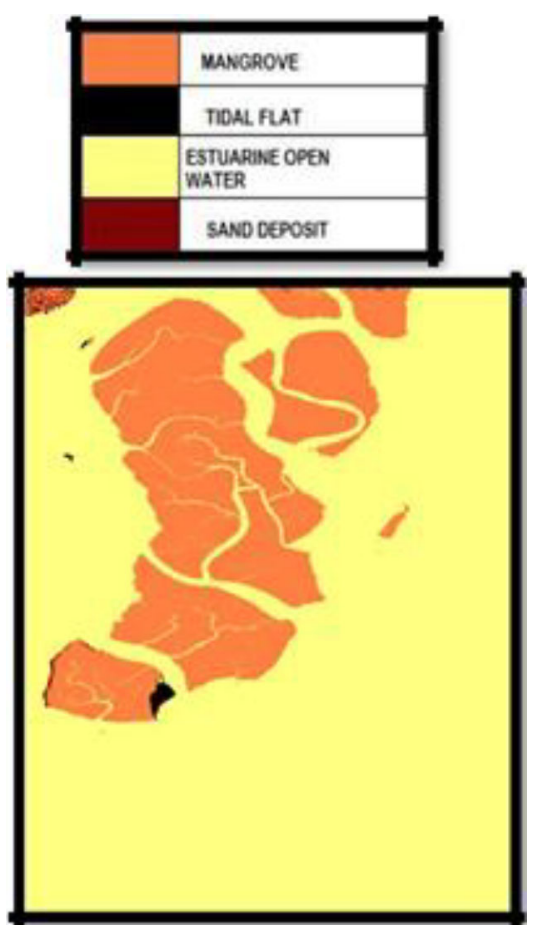

(b) Year-2016Figure3: Classified Images based on National Wetland Inventory (NWI) Classification scheme
The primary file input for SLAMM is the Digital Elevation Map DEM) and the National Wetland Inventory (NWI). Table 3 gives a summary of the input parameters used for our simulation. Mangrove is the only wetland type considered for tropical coastal system (Tropical Coastal systems are defined in the model as sites containing $0.5 \%$ or more total land coverage by mangroves)as per SLAMM 6.2.The balance of subsidence, sedimentation and eustatic sea level rise governs inundation parameter. The NWI files were generated using LANDSAT ETM + and LANDSAT 8 satellite image for the year 2001and 2016 respectively (figure 3 ). The process of classification aided by Google earth. The DEM file used is from advanced space-borne thermal emission and reflection radio meter or ASTER is provided in figure 4. Using the DEM file, the slope map of the area was produced with the help of ARC GIS. The slope of each cell is provided as an input, since the fraction of the cell that is converted to another wetland class is computed as a function of fraction of the cell inundated.
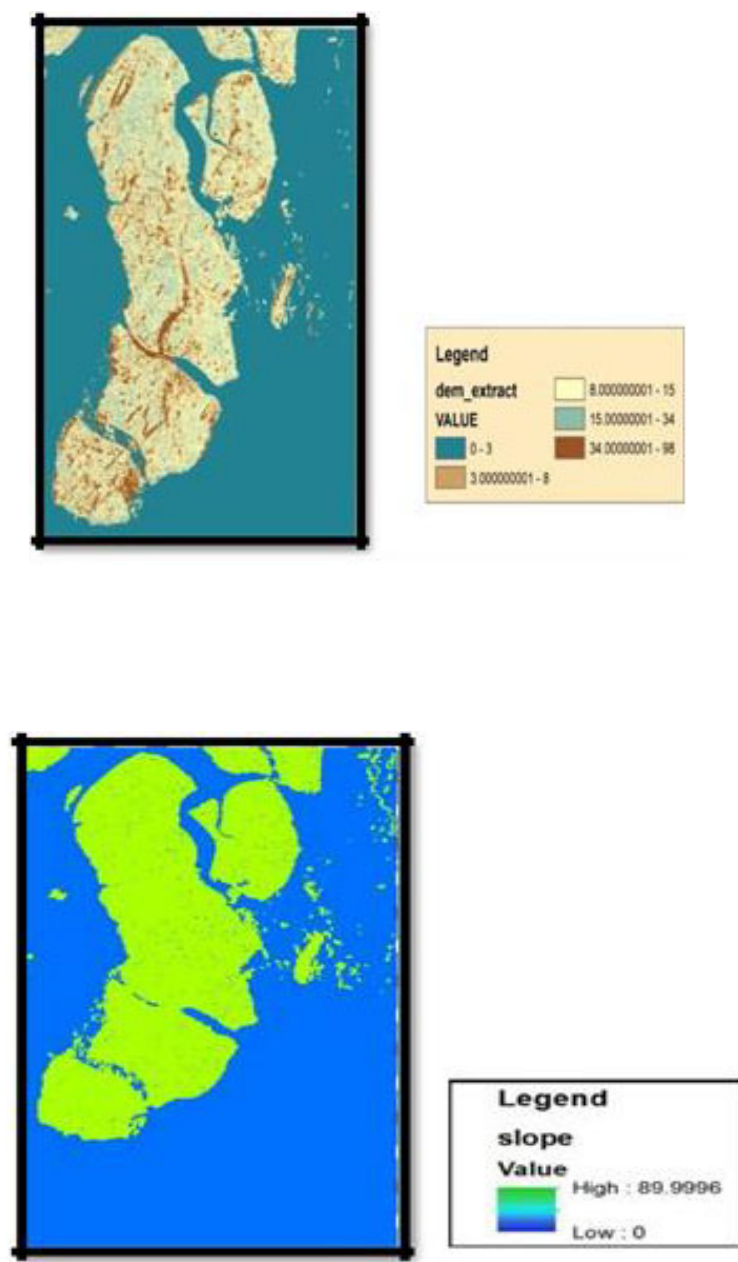
Figure 4: DEM and SLOPE of the study area (Source-ASTER)

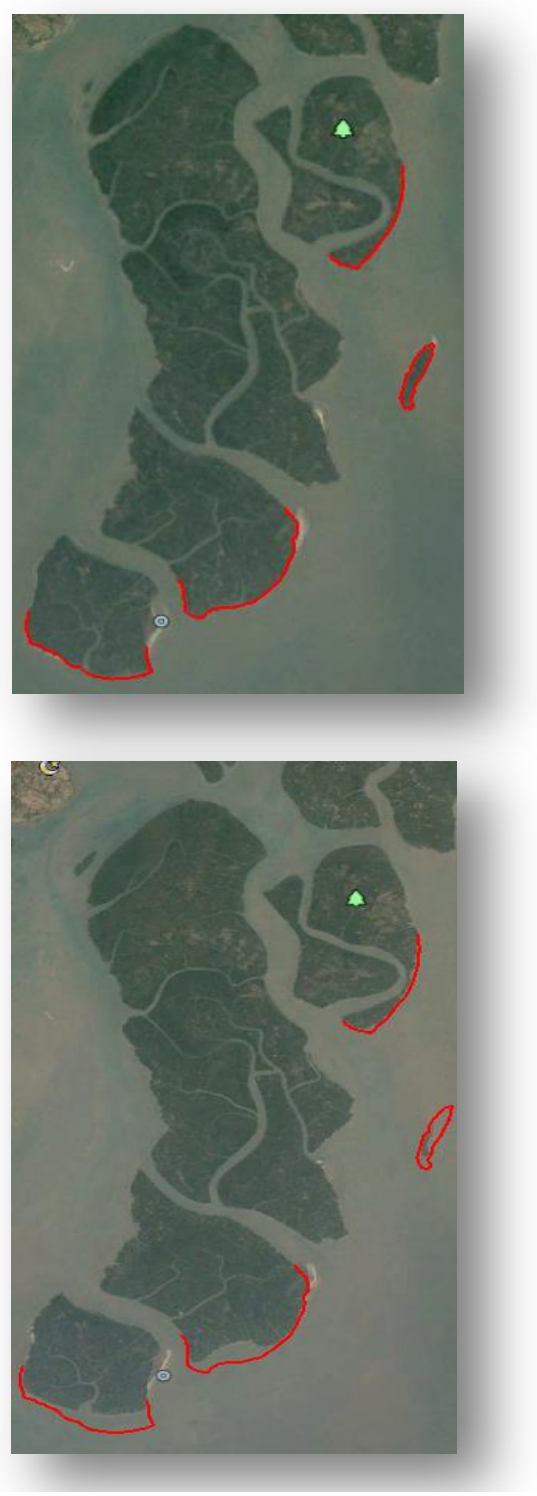

Figure 5: Google earth image of the year 2001 and 2016 demarcating estuarine beach and sand deposit (area drawn in red polygon) depicting real world scenario

\section{GREAT DIURNAL TIDAL RANGE}

The Great Diurnal Tidal Range is the difference between Mean Lower Low Water (mean of the lower low water height each day, hereinafter referred to as MLLW) and Mean Higher High Water (mean of the higher high water height each day, herein after referred to as MHHW). SLAMM predominantly designed for the micro tidal (diurnal) regions like the U.S. assumes the upper and lower limit of mangroves to be MHHW and MLLW respectively. Therefore, the changes in mangrove are primarily governed by the Great Diurnal Range.

The Sundarban on the other hand is a macro-tidal delta (mean tidal range $>4 \mathrm{~m}$ ) with predominantly semi-diurnal tides. If an assumption of GDTR of $4.5 \mathrm{~m}$ is taken, the lower elevation of the mangroves will be approximately $2.25 \mathrm{~m}$ below MSL (Payo, et al., 2016).This value might be adequate for many wetlands species in non-tropical regions, especially under micro-tidal conditions but it is unrealistic for the mangrove forest of the Sundarbans. Instead Mean Sea Level is a better representation of the lower limit of the mangroves as $99 \%$ of Mangroves area above MSL (Payo, et al., 2016). Thus, in the Sundarbans, we assume the GDTR to be $0 \mathrm{~m}$ indicating no amplification along tributaries.

Global mean sea-level rise projected as up to $0.98 \mathrm{~m}$ or greater by 2100 relative to the baseline period (1985-2005) (Payo, et al., 2016), we try to examine how well SLAMM will be able to depict these changes in the period of 2001 to 2016.

\section{SUBSIDENCE AND RELATIVE SEA-LEVEL SCENARIOS}

The Sundarban has a mean subsidence rate of $2.8 \mathrm{~mm} /$ year with highest and the lowest rates being $7.1 \mathrm{~mm} /$ year and $0.7 \mathrm{~mm} /$ year respectively (Brown \& Nicholls, 2015). This net subsidence is the result of intertwined effects of sedimentation, isostatic rebound and subsidence. A multitude of natural processes augmented by anthropogenic reasons which includes tectonics, changes in erosion control on a river or coast, sediment compaction, changes in farming practices (e.g. irrigation), deforestation, mining, groundwater or hydrocarbon extraction and changes to coastal management, such as levees or embankments may result in the net subsidence/uplift within an area. Subsidence/uplift of an area can impart drastic changes to the relative sea level rise. Thus average rate of annual mangrove loss from simulated mangrove changes for the moderate, medium and high sea-level scenarios and assuming net subsidence of $-2.5 \mathrm{~mm}$ shows the level of erosion and Inundation.

Table 4: Input Parameters with Value for SLAMM

\begin{tabular}{|c|c|c|}
\hline PARAIEIER & VALIE & SOtRCE \\
\hline $\begin{array}{l}\text { NW1Pboto } \\
\text { Date }\end{array}$ & 2000 & Clasefied using LANDSAT EDI+ Image \\
\hline DEMI & 2011 & ASTER \\
\hline $\begin{array}{l}\text { DRECTIOX } \\
\text { OFFSHORE }\end{array}$ & SOUTH & \\
\hline $\begin{array}{l}\text { HISTORIC } \\
\text { IREND }\end{array}$ & $3.24 \mathrm{me}$ yea & (Hama Ghosh DasGath \& Sen 2002) \\
\hline $\begin{array}{l}\text { MILDATTM } \\
\text { FORDEM }\end{array}$ & 0.031 & 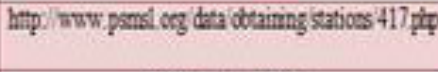 \\
\hline $\begin{array}{l}\text { GI DIRTAL } \\
\text { RAIGE }\end{array}$ & $0=$ & (Paye, ef al, 2016) \\
\hline $\begin{array}{l}\text { MLAVGROVE } \\
\text { ACCRETION }\end{array}$ & 7 mmyez & (Claboca Jay, If., \& Reted, 1999) \\
\hline $\begin{array}{l}\text { IDAL FLAI } \\
\text { EROSIOX } \\
\text { (HORIZONIAL) }\end{array}$ & 20 anyez & $\begin{array}{c}\text { (Ramman, Dragoti, \& El-Natri, 2011) } \\
\text { (Sarvar \& Woodrotfe, 2013) }\end{array}$ \\
\hline $\begin{array}{l}\text { SLR(ELSIATIC) } \\
\text { ABOVE PRESENT } \\
\text { VALCES BY } 2100\end{array}$ & $0.98 \mathrm{~m}$ & (Paye ex al, 2016) \\
\hline CEUL WITH & $30 \mathrm{~m}$ & LANDSAT Image \\
\hline
\end{tabular}




\section{RESULTS AND DISCUSSIONS:}

The first situation of $0 \mathrm{~mm} /$ year of subsidence/uplift rate was not able to depict the actual changes. A total erosion of about 1.20 sq.km was observed in the period of 2000 to 2016. But, under stable conditions, SLAMM was only able to depict around 0.05 sq.km of area change. However, when we increased the subsidence rate, the results were satisfactory. With increasing subsidence rate around the periphery of the islands, SLAMM was able to produce an erosion of about 1 sq. $\mathrm{km}$. We got this result at a subsidence rate of $4.5 \mathrm{~mm} /$ year to $5 \mathrm{~mm}$ /year which roughly matches the rates mentioned in the literature (Brown \& Nicholls, 2015). Most of the part of the islands, we considered here were in the range of $2 \mathrm{~m}$ to $6 \mathrm{~m}$ elevation from MSL (Figure 3.4). Thus, to cause severe erosion, there has to be a net subsidence within the area. MSL is assumed as a better proxy for lower elevation at which mangroves can be developed than MLLW and $0 \mathrm{~m}$ GDTR.

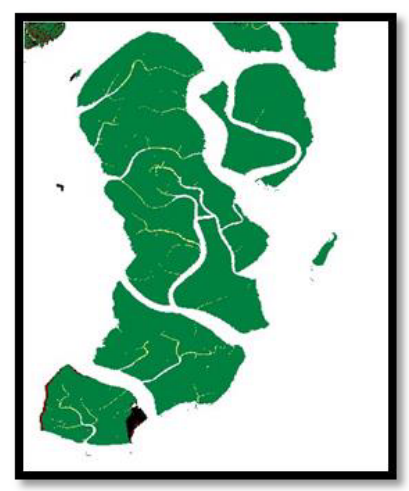

Figure 6: SLAMM output with SLR 0.5 metres and subsidence $5 \mathrm{~mm} /$ year

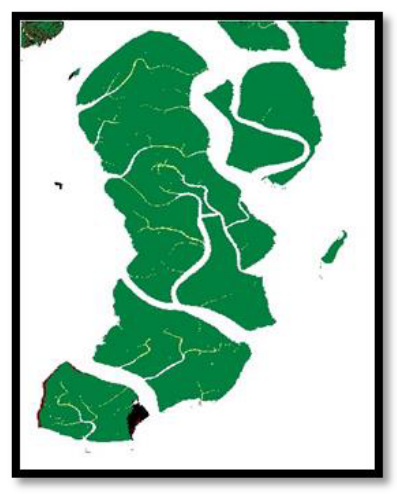

Figure 7: SLAMM output with SLR 0.5 metres and subsidence $6 \mathrm{~mm} /$ year

Further, since the erosion rates are high only towards the Southern part, the relative subsidence within that region should be high. This might be caused by the huge sediment accumulation within the periphery of the islands. The role of the long shore currents in this regard is worth mentioning. Due to the huge amount of sediment brought by these longshore currents from the SouthWestern side as well as an approximate sedimentation rate of (3$4 \mathrm{~mm} /$ year) by the river Ganga and Brahmaputra, a net subsidence is observed due to compaction. Further increase in the subsidence rates i.e. $>-5 \mathrm{~mm} /$ year increases the amount of erosion $(>1.20$ sq.km). Four main mechanisms are apparent in the GangaBrahmaputra delta: Tectonic subsidence/uplift (including neotectonics), compaction of sediment or peat (subsidence), anthropogenic subsidence, such as fluid extraction, drainage, embankment building, sedimentation (i.e. accretion or elevation gain) (Brown \& Nicholls, 2015). Thus the huge amount of sedimentation might not be the only reason for net subsidence in the region, but surely plays an important role among others.

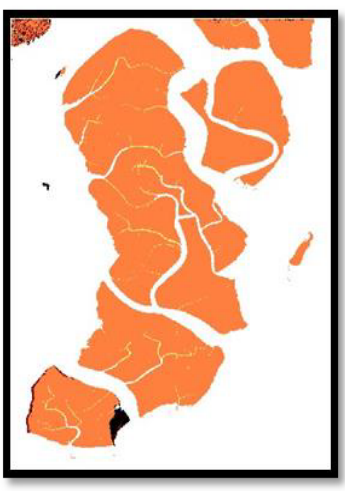

Figure 10: SLAMM output with SLR 1.5 meter and subsidence $3 \mathrm{~mm} /$ year

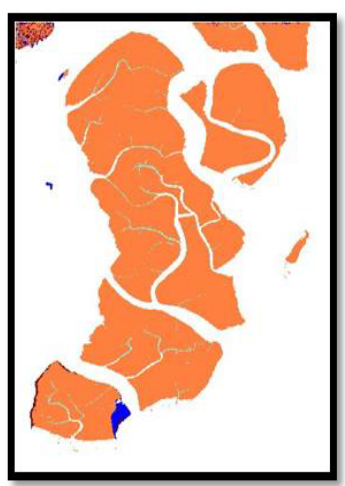

Figure 11: SLAMM output with SLR 1.5 meter and subsidence $4 \mathrm{~mm} /$ year

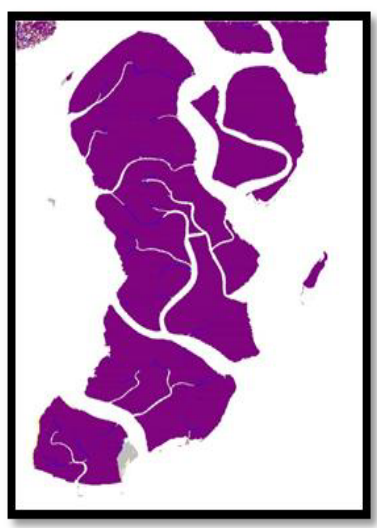

Figure8: SLAMM output with SLR 1 meter and subsidence $5 \mathrm{~mm} /$ year

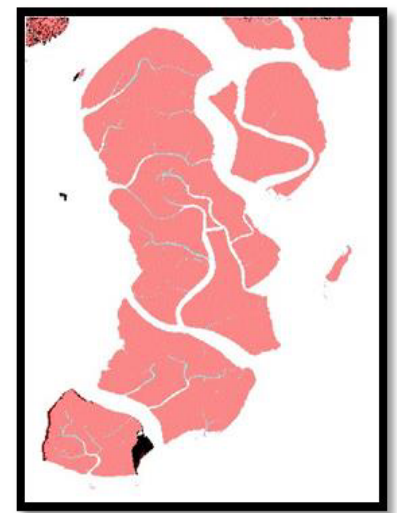

\section{CONCLUSION:}

The study gives a new and important perspective on the impact of SLR depending on the certain net subsidence rate. The results were satisfactory provided we have the required data for the region. If we are provided with the varying subsidence rates within the region, SLAMM can project some appreciable results in the case of erosion.

The main idea of this project is to analyze the different outcomes of running a simulation that was primarily designed for the microtidal regions. Thus SLAMM has been successfully applied in Indian scenario despite of unavailability of high resolution data which shows the accuracy and efficiency of this software.
Figure 9: SLAMM output with

SLR 1 meter and subsidence $4 \mathrm{~mm} /$ year 


\section{APPENDIX:}

\section{Future works}

Building on this study, further more detailed investigations of the Sundarban would be useful provided that availability of high definition DEM and high resolution data mostly LIDAR(as slamm was propounded in usa) the result can be more updated and accurate. Trial and error method can also be done in order to calculate the optimum level of subsidence, in case when the ground truth is not available.

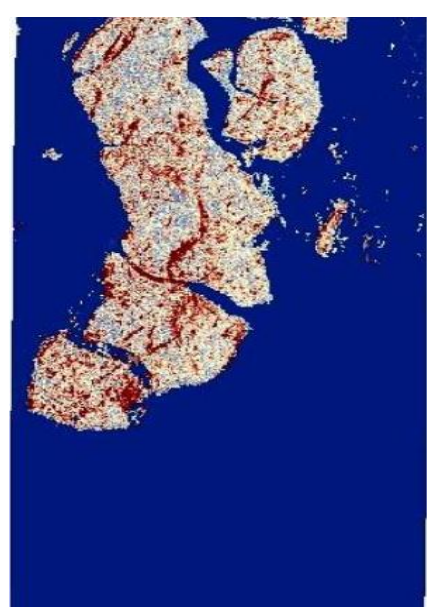

Figure 12: Generated high definition DEM

\section{REFERENCES}

References from journal:

- Payo, A., Mukhopadhyay, A., Hazra, S., Ghosh, T., Ghosh, S., Brown, S. . . Haque, A. (2016). "Projected changes in area of the Sundarban mangrove. Climatic Change, 279-291".

- Geselbracht, L., Freeman, K., Kelly, E., Gordon, D. R., \&Putz, F. E. (2011)."Retrospective and prospective model simulations.Climatic Change.

\section{References from Websites:}

- Warren Pinnacle Consulting, Inc., Sea-Level Affecting Marshes

Model(SLAMM), http://warrenpinnacle.com/prof/

SLAMM/index.html, retrieved on april,2017

- Landsat8DataUsersHandbook.pdf,

https:/landsat.usgs.gov/sites/default/files/documents/La ndsat8DataUsersHandbook.pdf, retrieved on apri1,2017

- USGS Earth Explorer data download portal, https://earthexplorer.usgs.gov/download/options, retrieved on april,2017 